\title{
LCD-based detection of enzymatic action $\uparrow$
}

\author{
Johan Hoogboom, $+*$ Kelly Velonia, $§$ Theo Rasing, Alan E. Rowan and Roeland J. M. Nolte
}

Received (in Cambridge, UK) 4th October 2005, Accepted 2nd November 2005

First published as an Advance Article on the web 24th November 2005

DOI: $10.1039 / b 514048 j$

By incorporating an ester-containing substrate in a selfassembled alignment layer for liquid crystal cells, the presence of a lipase (CALB) can be directly detected through its enzymatic action on the alignment layer, without the need for fluorescent labelling or enzyme assays.

Because of the strong interactions that exist between neighbouring liquid crystal domains on a surface, any change in their surface ordering is transmitted into the liquid crystal bulk, thereby amplifying a small disturbance by several orders of magnitude. ${ }^{1-11}$ This qualifies liquid crystals as molecular magnifying glasses, bringing (bio)reactions which occur on nanoscales into the realm of the naked eye, without the need for additional processing. ${ }^{1-11}$

Recently, we described a procedure for the preparation of selfassembled alignment layers for liquid crystal alignment purposes, which makes use of parallel nanometre-sized grooves that are present on commonly used indium-tin-oxide (ITO) surfaces. ${ }^{12}$ The size of these grooves is amplified over several orders of magnitude by the anisotropic grafting of oligosiloxanes, which spontaneously form in situ, onto the ITO surface, resulting in liquid crystal alignment over millimetre-sized areas. Here we expand on this procedure by incorporating siloxane $\mathbf{2}$ (for its synthesis see Scheme 1), which contains a hydrolysable group, into an alignment layer. When this layer is exposed to the lipase B from Candida antarctica (CALB), the subsequent partial hydrolysis of the layer results in a local disturbance of the alignment capabilities

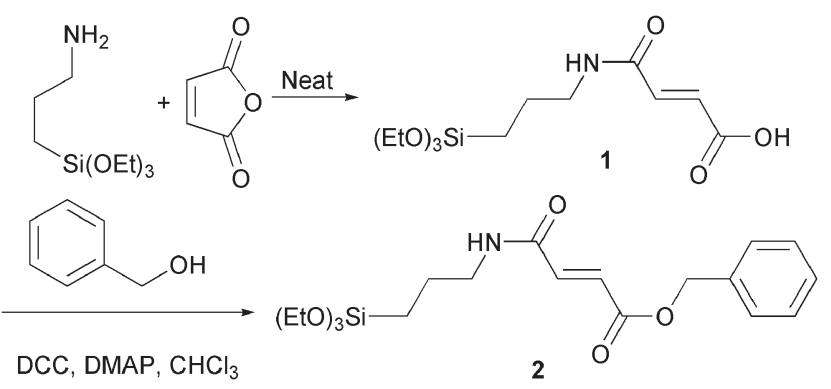

Scheme 1 Synthesis of $\mathbf{2}$

Institute for Molecules and Materials, Radboud University Nijmegen, Toernooiveld 1, 6525ED, Nijmegen, The Netherlands.

E-mail: J.Hoogboom@science.ru.nl; Fax: +31 24 3652929;

Tel: +31243652143

$\uparrow$ Electronic supplementary information (ESI) available: Synthesis \& molecular modeling. See DOI: 10.1039/b514048j

* Present address: Massachusetts Institute of Technology, 77 Massachusetts Avenue, Bldg 18-143, Cambridge, MA 02139, USA, hoogboom@mit.edu

$\S$ Present address: Department of Organic Chemistry, University of Geneva, Sciences II, 30 Quai Ernest Ansermet, CH-1211, Geneva 4, Switzerland. of the layer. When used in an LC cell, this was clearly visible by the absence of uniform liquid crystal alignment.

The substrate-containing alignment layer was constructed by immersing a cleaned ITO-plate into a $3 \mathrm{wt} \%$ solution of 2 and $\gamma$-aminopropyltriethoxysilane (APTES) in toluene in a 9:1 molar ratio. $\uparrow$ After $1 \mathrm{~h}$, the plate was removed from the solution, washed with acetonitrile and baked at $120{ }^{\circ} \mathrm{C}$ for $10 \mathrm{~min}$ to complete the covalent bonding of the siloxanes to the surface. When these surfaces were used in liquid crystal cells, ${ }^{11} \|$ polarising microscopy showed that the siloxane layers were capable of inducing uniform alignment of the common nematogen $n$-pentyl-4,4'-cyanobiphenyl, 5CB (Fig. 1a).

Prior to LC cell construction, this alignment layer was incubated with a solution of $0.3 \mathrm{mM}$ CALB in a $20 \mathrm{mM}$ phosphate buffer $\mathrm{pH} 8.0$, for $15 \mathrm{~h}$ in ambient conditions, after which it was washed with water, iso-propanol and acetone to remove any residual water, preventing dewetting of $5 \mathrm{CB}$. When such plates were used in the construction of a liquid crystal cell, polarising microscopy showed that the cell contained areas of circa $100 \mu \mathrm{m}$, in which the liquid crystal alignment had been disturbed (Fig. 1b). In addition, Fourier-Transform Infra-Red experiments indicated the presence of free acid groups on the parts of the surface which had been exposed to the enzyme. NMR experiments also showed that CALB was capable of hydrolysing $\mathbf{2}$ in solution. The patchy nature of enzymatic activity is comparable to burst kinetics observed before by Bjørnholm et al. for the action of a lipase on substrate-containing Langmuir-Blodgett-monolayers. ${ }^{13,14}$ Blank experiments, in which substrate-containing alignment layers were incubated for $15 \mathrm{~h}$ with a $20 \mathrm{mM}$ phosphate buffer $\mathrm{pH}$ 8.0, showed

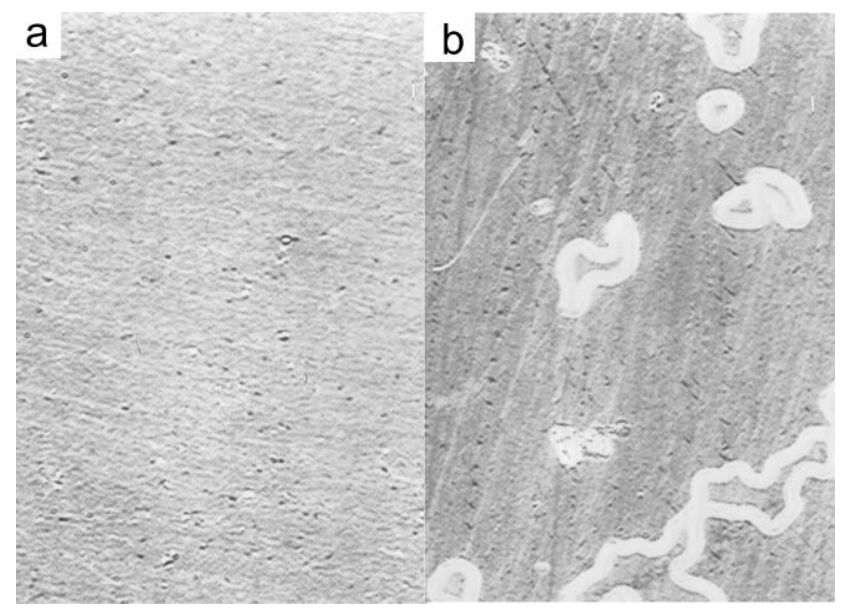

Fig. 1 Polarising micrographs of parallel liquid crystal cells with: (a) an alignment layer of $\mathbf{2}$ and APTES (see text), polarisers at $0^{\circ}$; (b) the same alignment layer, after exposure to CALB, polarisers at $45^{\circ}$. Images are 600 $\times 400 \mu \mathrm{m}$. 

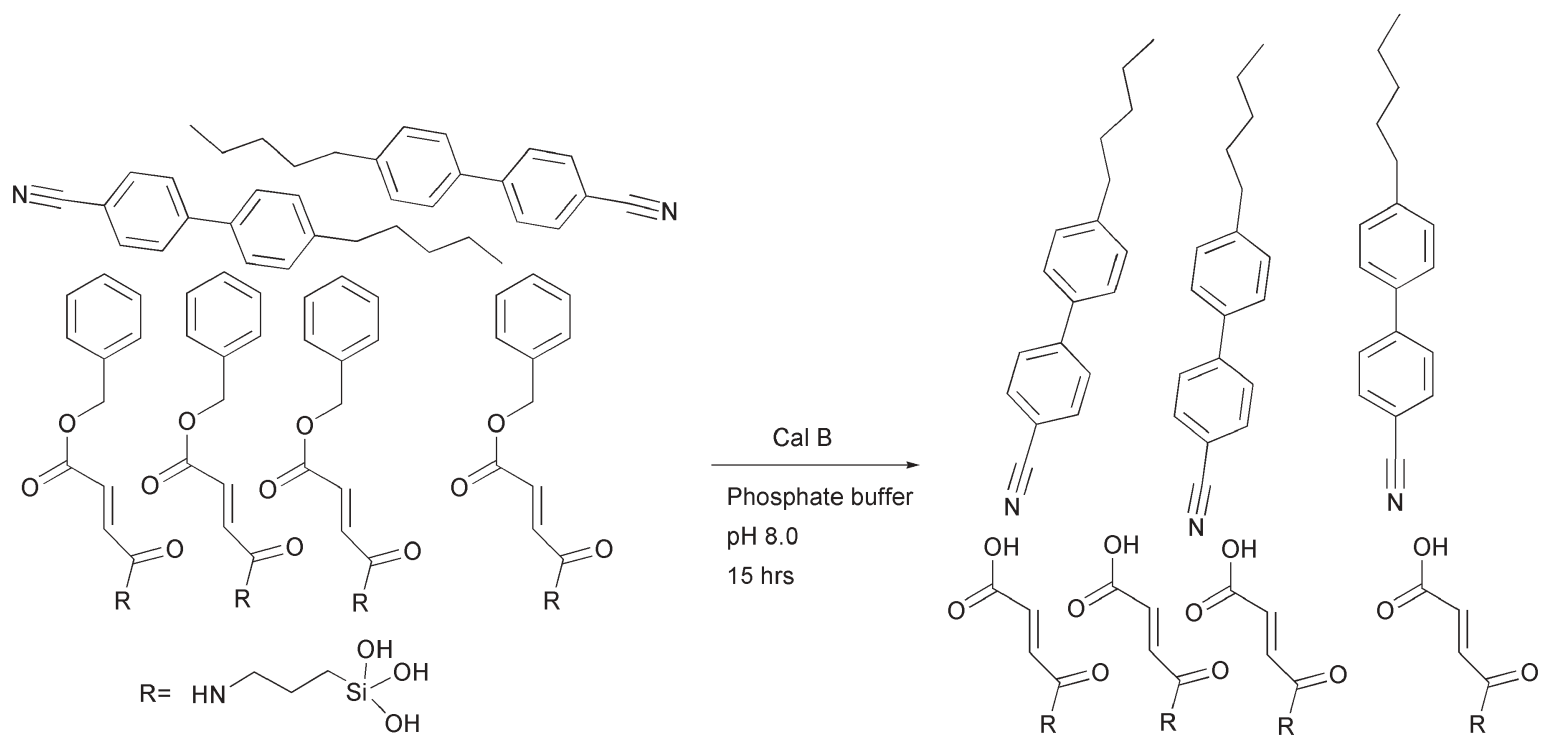

Scheme 2 Schematic depiction of possible extreme differences in local liquid crystal orientation, arising from polarity differences upon hydrolysis of the alignment layer, resulting in a reorientation of the mesogen near the boundary of enzymatic action and interfering with uniform liquid crystal alignment.

that a liquid crystal cell constructed from such plates contained no non-aligned regions larger than $10 \mu \mathrm{m}$, ruling out background hydrolysis. Scanning Electron Microscopy experiments indicated that the initial surface ordering, i.e. the groove direction dictated by the siloxane backbone of the alignment layer, ${ }^{12}$ was not affected by the enzymatic action.

These results can be explained as follows. Upon hydrolysis, the alignment layer undergoes a dramatic local change in polarity, going from a benzyl group to an acid group wherever the enzyme is active. This entails that the interaction between the alignment layer and the nematogen shifts from that between a benzyl group and the apolar parts of $5 \mathrm{CB}$, to one between an acid group and the polar part of $5 \mathrm{CB}$. This forces the mesogens near the surface, especially near the boundary of enzymatic activity, to adopt a different orientation (Scheme 2), disrupting uniform alignment. Such changes in mesogen orientation caused by polarity differences in the alignment layer are quite common and have been reported before. ${ }^{15-19}$ In turn, this altered ordering of the liquid crystal matrix near the surface is transferred into the mesogenic bulk and amplified up to levels that can be easily detected by the human eye.

The method we present here offers a way to detect the presence of a class of enzymes (e.g. lipases) by observing its action on a substrate-containing alignment layer. The method does not require additional labelling steps or enzymatic assays, can be easily performed and gives clearly visible results. We are currently investigating the use of different alignment layers for the detection of different classes of enzymes, as well as determining a lower limit on the detectable enzyme concentration in relation to reaction time. We are also investigating the possibility of using this technique to create surface patterns.

\section{Notes and references}

- The formation of the alignment layer is very sensitive to the oligosiloxane oligomerisation rate: the presence of the correct oligomer size at the right time during layer formation, is crucial to the creation of an ordered surface. ${ }^{12}$ To tune this rate, other siloxanes with different kinetics, such as APTES, were added.

II LC cells were prepared by using one sample plate and an unrubbed counter plate which was spin-coated with Polyimide Pyralin PI2555 (HD Microsystems) at $5000 \mathrm{rpm}$ for $20 \mathrm{~s}$ and baked at $120{ }^{\circ} \mathrm{C}$ for $90 \mathrm{~min}$. Mylar spacers of $6 \mu \mathrm{m}$ were used to separate the plates. ITO plates were cleaned with ozone $\left(100 \mathrm{~h}^{-1}\right)$ for $3 \mathrm{~h}$ prior to use. LC cells were filled with $5 \mathrm{CB}$ in the isotropic phase at $40{ }^{\circ} \mathrm{C}\left(T_{\mathrm{NI}}=35.3{ }^{\circ} \mathrm{C}\right)$ and were cycled $3 \times$ between $20{ }^{\circ} \mathrm{C}$ and $40{ }^{\circ} \mathrm{C}$ to exclude any memory effects.

1 Y.-Y. Luk, M. L. Tingley, D. J. Hall, B. A. Israel, C. J. Murphy, P. J. Bertics and N. L. Abbott, Langmuir, 2003, 19, 1671.

2 J. A. Van Nelson, S.-R. Kim and N. L. Abbott, Langmuir, 2002, 18, 5031.

3 V. K. Gupta, J. J. Skaife, T. Dubrovsky and N. L. Abbott, Science, 1998, 279, 2077.

4 S.-R. Kim and N. L. Abbott, Langmuir, 2002, 18, 5269.

5 M. L. Tingey, Y-Y. Luk and N. L. Abbott, Adv. Mater., 2002, 14, 1224.

6 N. L. Abbott, J. J. Skaife, V. K. Gupta, T. B. Dubrovsky and R. Shah, US Patent No. 6,284,197 and WO 99/63329.

7 R. R. Shah and N. L. Abbott, Langmuir, 2003, 29, 275.

8 Y.-Y. Luk and N. L. Abbott, Curr. Opin. Colloid Interface Sci., 2002, 7, 267.

9 F. L. Dickert, U. P. A. Bäumler and G. K. Zwissler, Synth. Met., 1993, 61, 1-2, 47 .

10 C. J. Woolverton, G. D. Niehaus, K. J. Doane, O. Lavrentovich, S. P. Schmidt and S. A. Signs, WO 99/64862.

11 J. Hoogboom, J. Clerx, M. B. J. Otten, A. E. Rowan, T. Rasing and R. J. M. Nolte, Chem. Commun., 2003, 2856.

12 J. Hoogboom, M. Behdani, J. A. A. W. Elemans, M. A. C. Devillers, R. de Gelder, A. E. Rowan, T. Rasing and R. J. M. Nolte, Angew. Chem., Int. Ed., 2003, 42, 1812.

13 K. Balashev, T. R. Jensen, K. Kjear and T. Bjørnholm, Biochimie, 2001, 83, 387.

14 K. Balashev, M. Gudmand, L. Iversen, T. H. Callisen, A. Svendsen and T. Bjørnholm, Biochim. Biophys. Acta, 2003, 1615, 93.

15 K.-W. Lee, S.-H. Paek, A. Lien, C. Durning and H. Fukuro, Macromolecules, 1996, 29, 8894.

16 J. J. Ge, C. Y. Li, G. Xue, I. K. Mann, D. Zhang, S.-H. Wang, F. W. Harris, S. Z. D. Cheng, S.-C. Hong, X. Zhuang and Y. R. Shen, J. Am. Chem. Soc., 2001, 123, 5768.

17 B. Jérôme, J. O'Brien, Y. Ouchi, C. Stanners and Y. R. Shen, Phys. Rev. Lett., 1993, 71, 758.

18 M. Barmentlo, F. R. Hoekstra, N. P. Willard and R. W. J. Hollering, Phys. Rev. A, 1991, 43, 5740 .

19 S.-K. Oh, M. Nakagawa and K. Ichimura, J. Mater. Chem., 2001, 11, 1563. 